\title{
Cationic Copolymerization of 2-Chloroethyl Vinyl Ether with Styrene Derivatives
}

\author{
Tadashi Masuda, Toshinobu Higashimura, and Seizo Okamura \\ Department of Polymer Chemistry, Kyoto University, Kyoto, Japan.
}

(Received July 31, 1969)

\begin{abstract}
The possibility of copolymer formation and the effect of polymerization conditions on monomer reactivity ratios (MRR) were investigated for cationic copolymerizations of a vinyl ether with styrene derivatives. 2-Chloroethyl vinyl ether (CEVE) was used as the vinyl ether, and $p$-methoxystyrene ( $p$ MOS), $p$-methylstyrene ( $p \mathrm{MS}$ ) and $\alpha$-methylstyrene $(\alpha \mathrm{MS})$ as styrene derivatives. Copolymerization was carried out in toluene or methylene chloride, being catalyzed by $\mathrm{BF}_{3} \cdot \mathrm{O}\left(\mathrm{C}_{2} \mathrm{H}_{5}\right)_{2}$ or $\mathrm{SnCl}_{4} \cdot \mathrm{CCl}_{3} \mathrm{CO}_{2} \mathrm{H}$ at $-78^{\circ} \mathrm{C}$. The copolymer composition was determined from each monomer consumption through gas chromatography. The copolymer formation was confirmed by fractionation and NMR spectrum of the product. In CEVE- $\alpha \mathrm{MS}$ system, the relative reactivity of each monomer was independent of the kind of the propagating chain ends $\left(r_{1} \times r_{2} \cong 1\right)$. In contrast, composition curves showed an $\mathrm{S}$ shape in CEVE- $p$ MOS and CEVE- $p$ MS systems $\left(r_{1} \times r_{2}>1\right)$. This difference may be attributed to the difference in stability between the growing carbonium ions of $\alpha \mathrm{MS}$ and the ring-substituted styrenes. It was found that polymerization conditions significantly affect MRR; the CEVE content in the copolymer was greater for $\mathrm{BF}_{3} \cdot \mathrm{O}\left(\mathrm{C}_{2} \mathrm{H}_{5}\right)_{2}$ than for $\mathrm{SnCl}_{4}$. $\mathrm{CCl}_{3} \mathrm{CO}_{2} \mathrm{H}$, and greater in toluene than in methylene chloride.

KEY WORDS Cationic Copolymerization / 2-Chloroethyl Vinyl

Ether / $p$-Methylstyrene / $p$-Methoxystyrene / $\alpha$-Methylstyrene / Monomer Reactivity Ratio / Copolymer Formation /
\end{abstract}

Styrene derivatives and vinyl ethers are representative monomers which are polymerized in cationic mechanism and have been made use of widely for the study of cationic polymerization. Many cationic copolymerizations between styrene derivatives have been carried out, and the products of monomer reactivity ratios $\left(r_{1} \times r_{2}\right)$ were found to be approximately unity. ${ }^{1,2}$ This holds also in the copolymerization between vinyl ethers, ${ }^{3-7}$ though data are not abundant.

On the other hand, the authors found that the copolymer composition curves show an appreciable S-shape (namely, $r_{1}>1$ and $r_{2}>1$ ) in the copolymerization of vinyl ether with $p$-methoxystyrene ( $p$ MOS) and $p$-methylstyrene ( $p$ MS) by iodine. ${ }^{5}$ However, Marvel et al. ${ }^{4}$ and Pepper et al. ${ }^{8}$ copolymerized $\alpha$-methylstyrene ( $\alpha \mathrm{MS}$ ) or its derivatives with 2-chloroethyl vinyl ether (CEVE), finding the result that the product $r_{1} \times r_{2}$ was not much greater than unity. Pepper et al. suggested that the difference in our results was partly due to the difference of the polymerization conditions, e.g. the kind of catalyst.
However, the phenomenon that both $r_{1}$ and $r_{2}$ are larger than unity was observed also in the cationic polymerization of isobutene with styrene. ${ }^{9}$ This suggests that the cross-propagation is difficult in the cationic copolymerization between monomers with a different type of substituent.

In this paper, to elucidate the cause of discrepancies of the kinetic behavior between ringsubstituted styrenes and $\alpha \mathrm{MS}$ in cationic copolymerization with CEVE, it was first studied whether or not a copolymer would be produced in the cationic copolymerization of CEVE with styrene derivatives. As the copolymer formation was confirmed, these monomers were copolymerized in various conditions and the behavior of ringsubstituted styrenes was compared with that of $\alpha$ MS. Further, the dependence of the monomer reactivity ratio on the kind of solvents and catalysts used was studied.

\section{EXPERIMENTAL}

\section{Materials \\ $p \mathrm{MOS}$ and $p \mathrm{MS}$ were synthesized from anisole}


and toluene respectively, through acetylation, reduction and dehydration procedures as described in the previous paper. ${ }^{10}$ These monomers and commercial $\alpha \mathrm{MS}$ and CEVE were purified by washing with $10 \%$ aqueous solution of sodium hydroxide and water, drying and distilling twice over calcium hydride. The purities of these monomers were found to be more than $99.8 \%$ through gas chromatography.

Solvents and catalysts were purified by the usual methods.

\section{Procedures}

\section{Polymerization}

The copolymerization was initiated by adding the catalyst solution from a syringe through a rubber stopper into a flask containing the monomer solution. After a certain time, polymerization was stopped by methanol containing a small amount of diethylamine. The residual monomer concentration was determined by gas chromatography (Yanagimoto GCG 550T). Column materials and internal standards were selected so as to suit the determination of each monomer. For example, measurement conditions of CEVE- $p$ MOS system were as follows;

\begin{tabular}{ccccc}
\hline $\begin{array}{c}\text { Mono- } \\
\text { mer }\end{array}$ & $\begin{array}{c}\text { Carrier } \\
\text { gas }\end{array}$ & $\begin{array}{c}\text { Column } \\
\text { material }\end{array}$ & $\begin{array}{c}\text { Internal }^{\mathrm{b}} \\
\text { standard }^{2}\end{array}$ & $\begin{array}{c}\text { Column } \\
\text { temp. }\left({ }^{\circ} \mathrm{C}\right)\end{array}$ \\
\hline $\mathrm{CEVE}$ & $\mathrm{H}_{2}$ & $\begin{array}{c}25 \% \mathrm{PEG}^{\mathrm{a}} \\
1500 \mathrm{C}-22 \\
(1.5 \mathrm{~m})\end{array}$ & $\mathrm{PhCH}_{3}$ & 65 \\
& & $\begin{array}{c}25 \% \mathrm{PEG}^{\mathrm{a}} \\
400 \mathrm{C}-22 \\
(0.75 \mathrm{~m})\end{array}$ & $\mathrm{PhNO}_{2}$ & 120 \\
\hline $\mathrm{MOS}$ & $\mathrm{H}_{2}$ & $\begin{array}{c} \\
\end{array}$ & & \\
\hline
\end{tabular}

a Poly (ethylene glycol)

b 2 vol $\%$ of reaction solution

\section{Molecular Weight of Polymer}

Viscosity number $\left(\eta_{s p} / C ; \quad C=1.00 \mathrm{~g} / 100 \mathrm{~m} l\right.$ solution) was measured in benzene solution at $30^{\circ} \mathrm{C}$. Molecular weight was measured at $60^{\circ} \mathrm{C}$ in a cyclohexanone solution by the osmometric method.

\section{Confirmation of Copolymer Formation}

The turbidimetric titration was carried out with a Shimadzu TG21 turbidimeter. NMR spectra of polymer were measured by a Varian HR-60 Spectrometer.

\section{RESULTS}

\section{Confirmation of Copolymer Formation}

a. Viscosity and Molecular Weight

Methanol-insoluble polymer was produced in the copolymerization of CEVE and styrene

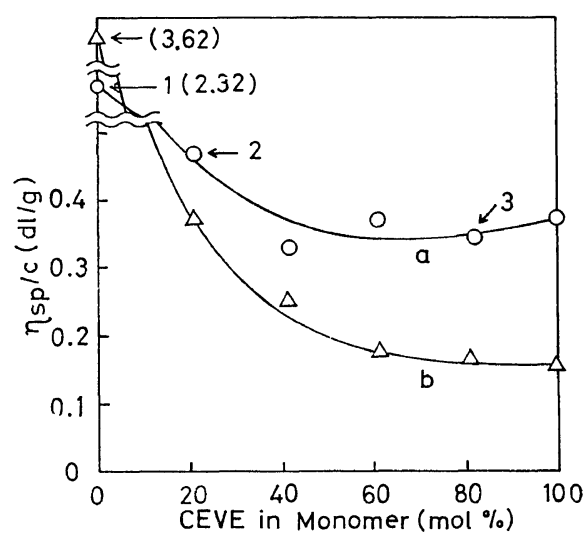

Figure 1. Relationship between monomer composition and viscosity number of polymer obtained in copolymerization of CEVE with $p$ MOS.

(Polymerization conditions,

$[\mathrm{M}]_{0} 0.50 \mathrm{~mol} / \mathrm{l}$, Solvent: $\mathrm{CH}_{2} \mathrm{Cl}_{2},-78^{\circ} \mathrm{C}$, Conversion $>80 \%$, Catalyst: $\mathrm{a}(\mathrm{O}) ; \mathrm{BF}_{3}$. $\left.\mathrm{OEt}_{2}, \mathrm{~b}(\triangle) ; \mathrm{SnCl}_{4} \cdot \mathrm{CCl}_{3} \mathrm{CO}_{2} \mathrm{H}\right)$.

Molecular weights of polymers 1-3 were measured by the osmotic pressure method.

No. $\begin{array}{lr}1 M_{n}, & 165000 \\ 2 & 49000 \\ 3 & 37700 .\end{array}$

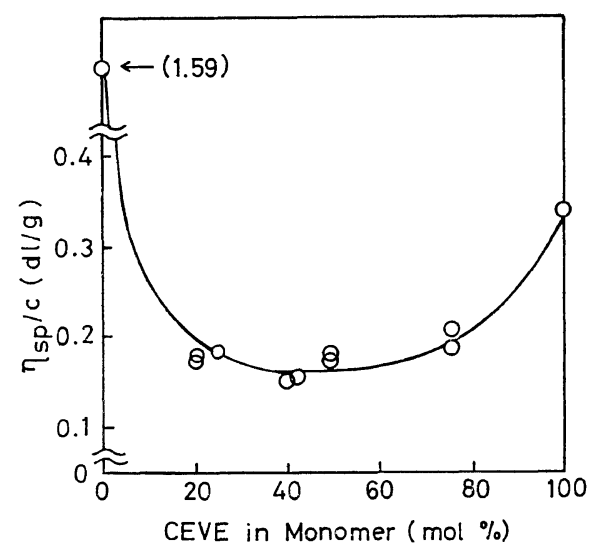

Figure 2. Relationship between monomer compositon and viscosity number of polymer obtained in copolymerization of CEVE with $\alpha \mathrm{MS}$.

(Polymerization conditions,

[M] $]_{0} 0.50 \mathrm{~mol} / l$, Solvent: $\mathrm{CH}_{2} \mathrm{Cl}_{2}$, Catalyst: $\mathrm{BF}_{3} . \mathrm{OEt}_{2},-78^{\circ} \mathrm{C}$, Conversion $>80 \%$ ).

Polymer J., Vol. 1, No. 1, 1970 
Cationic Copolymerization of CEVE with Styrenes

Table I. Fractionation of CEVE-pMOS polymer ${ }^{\mathrm{a}}$

\begin{tabular}{cccccc}
\hline & Sample No. & 1 & 2 & 3 & $4^{\mathrm{b}}$ \\
\hline \multirow{3}{*}{$\begin{array}{c}\text { Catalyst } \\
\text { Monomer }\end{array}$} & $\left([\mathrm{CEVE}]_{0}:[p \mathrm{MOS}]_{0}\right)$ & $\mathrm{BF}_{3} \cdot \mathrm{OEt}_{2}$ & $\mathrm{BF}_{3} \cdot \mathrm{OEt}_{2}$ & $\mathrm{SnCl}_{4} \cdot \mathrm{TCA}^{\mathrm{d}}$ & - \\
\hline Fractions & & $40: 60$ & $60: 40$ & $70: 30$ & - \\
$($ wt $\%$ ) & Soluble part & 17.0 & 21.5 & 57.1 & 47.0 \\
\hline CEVE content in & Insoluble part & 78.0 & 75.0 & 38.1 & 47.7 \\
polymer & Original polymer & 30.4 & 53.5 & 65.3 & 49.2 \\
(wt \%) & Soluble part & 62.7 & 78.0 & 80.1 & 95.9 \\
\hline
\end{tabular}

${ }^{a}$ Polymerization conditions, $[\mathrm{M}]_{0} 0.50 \mathrm{~mol} / l$, Solvent: $\mathrm{CH}_{2} \mathrm{Cl}_{2},-78^{\circ} \mathrm{C}$, Conversion $70-90 \%$ ).

b A mixture of equivalent weight of poly (CEVE) and poly ( $p$ MOS).

c Loss of polymer in this procedure was $c a .5 \mathrm{wt} \%$.

d TCA: Trichloroacetic acid.

derivatives. The yield of the methanol-insoluble polymer coincided with monomer consumption within $\pm 2 \%$ error. The dependence of viscosity number on monomer composition is shown in Figures 1 and 2. As is seen in the cationic copolymerization of styrene derivatives with isobutene, the molecular weight of copolymer was smaller than that expected for homopolymers.

\section{b. Fractionation}

Fractionation of polymers obtained at high conversion was carried out to determine whether or not copolymer is formed in the polymerization of vinyl ether and styrene derivatives. The polymer obtained in the copolymerization of CEVE with $p$ MOS was separated with an equivolume mixture of acetone and methanol into soluble and insoluble parts at $30^{\circ} \mathrm{C}$. Composition of each part is shown in Table I.

As is seen from Table I, poly ( $p$ MOS) was scarcely dissolved in this solvent and poly (CEVE) was dissolved completely. Nevertheless, both soluble and insoluble parts of the polymer obtained in copolymerization contained both CEVE and $p$ MOS units. Similar results were observed in the polymers obtained in the copolymerization of CEVE with $\alpha \mathrm{MS}$ and of CEVE with $p \mathrm{MS}$. These results show the formation of the copolymer in the cationic copolymerization of styrene derivatives with CEVE.

\section{c. Turbidimetric Titration}

The change of turbidity was measured at the time of the addition of petroleum ether as nonsolvent to a benzene solution of the polymer obtained in CEVE- $\alpha$ MS copolymerization. As is

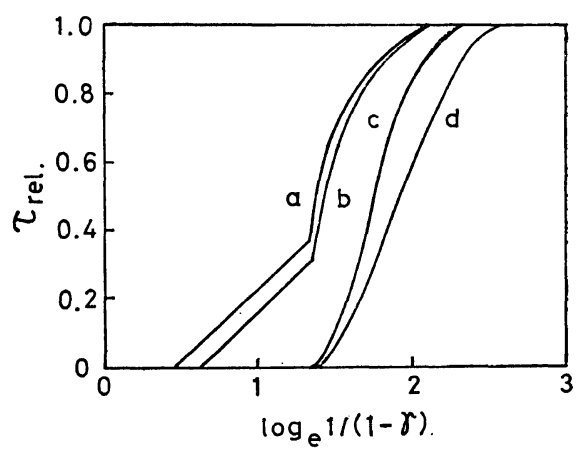

Figure 3. Turbidimetric titration curves of CEVE$\alpha \mathrm{MS}$ copolymer and the mixture of poly (CEVE) and poly $(\alpha \mathrm{MS})$ at room temperature.

Polymer concentration; $8 \mathrm{mg} / \mathrm{d} l$ benzene,

a: Poly ( $\alpha \mathrm{MS})$-Poly (CEVE) (cryst.) mixture,

b: Poly( $\alpha$ MS)-Poly (CEVE) (amorph.) mixture,

c and d: Copolymer of $\alpha$ MS-CEVE obtained in $\mathrm{CH}_{2} \mathrm{Cl}_{2}$ catalyzed by $\mathrm{SnCl}_{4} \cdot \mathrm{CCl}_{3} \mathrm{CO}_{2} \mathrm{H}$ and $\mathrm{BF}_{3} \cdot \mathrm{OEt}_{2}$, respectively.

seen from Figure 3 the curves for the polymers obtained in the copolymerization were very different from those for the mixtures of homopolymers; although the copolymer solution began to be turbid at the same $\gamma$-value (the volume ratio of non-solvent to the sum of solvent and nonsolvent) as that of poly ( $\alpha \mathrm{MS})$, the change of turbidity was slow as in poly (CEVE) and the endpoint of precipitation $\left(\tau_{\mathrm{rel}}=1.0\right)$ was observed at a higher $\gamma$-value than the mixture of homopolymer. 


\section{d. NMR Spectra}

Copolymer formation was also confirmed by the NMR spectrum. The spectra are shown in Figures 4 and 5 for CEVE- $\alpha$ MS and CEVE- $p$ MS polymer, respectively. Figure 4 a shows the spectrum of a mixture of poly (CEVE) and poly ( $\alpha \mathrm{MS})$, which coincides well with superposition of the spectrum of each homopolymer.

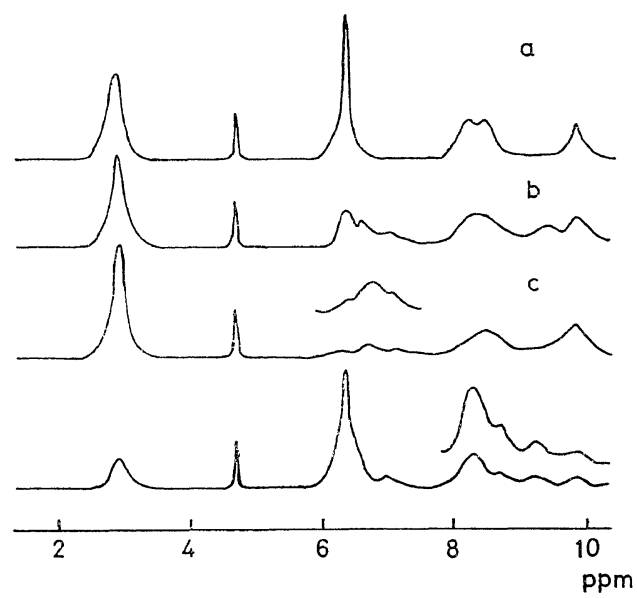

Figure 4. NMR spectra of CEVE- $\alpha \mathrm{MS}$ polymers obtained by $\mathrm{SnCl}_{4} \cdot \mathrm{CCl}_{3} \mathrm{CO}_{2} \mathrm{H}$.

(Solvent: $\mathrm{CDCl}_{3}$, Internal standard: $\mathrm{CH}_{2} \mathrm{Cl}_{2}$, Polymer concentration $10 \%, 24^{\circ} \mathrm{C}$ ).

Polymerization conditions are the same as in Figure 2.

a: Mixture of poly (CEVE) and ploy ( $\alpha \mathrm{MS})$, Copolymer; Monomer composition in feed ([CEVE]: $[\alpha \mathrm{MS}]$,

b: $40: 60$, c: $20: 80, \mathrm{~d}: 80: 20$.

On the other hand, in CEVE- $\alpha$ MS copolymer many other peaks $(\tau 6.53,6.91,8.74$, and 9.38) based on the difference of the neighbouring monomer unit were observed and two peaks at $\tau 8.22$ and 8.38 became one broad peak at $\tau 8.30$. These changes of NMR spectra suggest the formation of a true copolymer. The peaks at $\tau 6.53$ and 6.91 are considered to be the shifted ones of alkoxyl and/or methine protons through shielding by phenyl groups on either or both sides. The peak of $\alpha$-methyl protons at $\tau 9.81$ was also shifted to $\tau 9.38$ and 8.74 by the change of the neighbouring monomer unit.

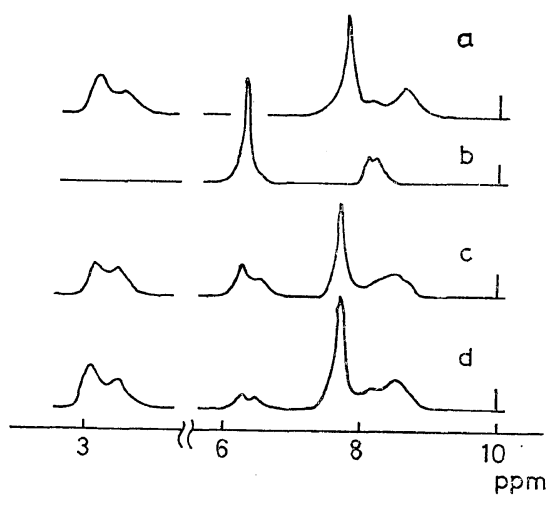

Figure 5. NMR spectra of CEVE- $p$ MS polymers obtained by $\mathrm{SnCl}_{4} \cdot \mathrm{CCl}_{3} \mathrm{CO}_{2} \mathrm{H}$.

(Solvent: $\mathrm{CDCl}_{3}$, Internal standard: TMS, Polymer concentration $10 \%, 80^{\circ} \mathrm{C}$ ).

Polymerization conditions are the same as in Figure 2. a: $\operatorname{Poly}(p M S), b$ : Poly(CEVE),

Copolymer; Monomer composition in feed ([CEVE]: $[p \mathrm{MS}]$ ), c; 45: 55, d; $15: 85$.

As to CEVE-pMS polymer (Figure $5 c$ ), a new peak at $\tau 6.60$ which was absent in both homopolymers was observed. This is thought to appear because of shifting of alkoxyl and/or methine protons due to the presence of $p \mathrm{MS}$ units on either one or both sides. In the case of CEVE-pMOS polymer, the production of a copolymer was not confirmed, because of the overlap of spectra of alkoxyl, methine and $p$ methoxyl protons.

Relative Reactivity of CEVE and Styrene Derivatives in the Cationic Copolymerization

a. Copolymerization of CEVE with Ring- substituted Styrenes

Methylene chloride and toluene were used as polar and non-polar solvents, respectively. Boron trifluoride etherate $\left(\mathrm{BF}_{3} \cdot \mathrm{O}\left(\mathrm{C}_{2} \mathrm{H}_{5}\right)_{2}\right)$ and stannic chloride (with equimolar trichloroacetic acid $\left(\mathrm{CCl}_{3} \mathrm{CO}_{2} \mathrm{H}\right)$ as cocatalyst) were used as catalysts. Polymerization was carried out at $-78^{\circ} \mathrm{C}$. $\mathrm{Al}$ though the reaction system contained $1-2 \mathrm{mmol} / \mathrm{l}$ of water in this case, the small amount of water did not affect the monomer reactivity ratio (MRR).

To avoid experimental error for the gas-chloromatographic measurement of residual monomer 


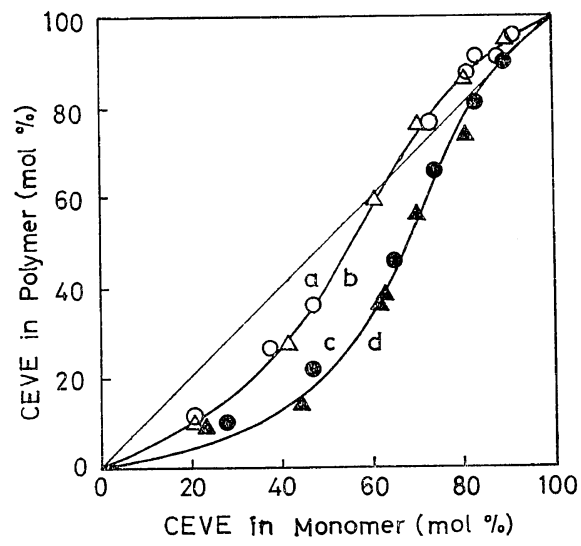

Figure 6. Copolymer composition curves of CEVE with $p$ MOS.

$\left([\mathrm{M}]_{0} 0.50 \mathrm{~mol} / \mathrm{l},-78^{\circ} \mathrm{C}\right)$

$\mathrm{a}(\mathrm{O}): \mathrm{BF}_{3} . \mathrm{OEt}_{2}, \mathrm{C}_{6} \mathrm{H}_{5} \mathrm{CH}_{3}, \mathrm{~b}(\triangle): \mathrm{BF}_{3}$. $\mathrm{OEt}_{2}, \quad \mathrm{CH}_{2} \mathrm{Cl}_{2}, \mathrm{c}\left(\mathrm{B}_{)}\right): \mathrm{SnCl}_{4} \cdot \mathrm{CCl}_{3} \mathrm{CO}_{2} \mathrm{H}$, $\mathrm{C}_{6} \mathrm{H}_{5} \mathrm{CH}_{3}, \mathrm{~d}(\mathbf{\Delta}): \mathrm{SnCl}_{4} \cdot \mathrm{CCl}_{3} \mathrm{CO}_{2} \mathrm{H}, \mathrm{CH}_{2} \mathrm{Cl}_{2}$.

concentration, conversion was restricted to 20$30 \%$. The mathematical average value of initial and final monomer concentration was taken as the monomer concentration to obtain the copolymer composition curves. It afforded a much better result than using initial monomer concentration as the monomer concentration.

In Figure 6 are shown copolymer composition curves of CEVE-pMOS copolymerization. $p \mathrm{MOS}$ was more reactive than CEVE in equimolar copolymerization. It is also apparent that the composition curves are typically S-shaped, which means that MRR, both $r_{1}$ and $r_{2}$, are greater than unity and that cross-propagation is difficult. Copolymer composition was not affected by the kind of solvent, but affected by the kind of catalyst.

As is clear from Figure 7, $p$ MS was less reactive than CEVE. In this case, also the tendency for the product $r_{1} \times r_{2}$ to exceed unity was observed. $p$ MS content in the copolymer was larger in methylene chloride than in toluene, and with $\mathrm{SnCl}_{4} \cdot \mathrm{CCl}_{3} \mathrm{CO}_{2} \mathrm{H}$ than with $\mathrm{BF}_{3} \cdot \mathrm{O}\left(\mathrm{C}_{2} \mathrm{H}_{5}\right)_{2}$. The relative reactivity of $p \mathrm{MS}$ against $\mathrm{CEVE}$ was about half in methylene chloride with $\mathrm{SnCl}_{4} \cdot \mathrm{CCl}_{3}$ $\mathrm{CO}_{2} \mathrm{H}$, but surprisingly small in toluene with $\mathrm{BF}_{3} \cdot \mathrm{O}\left(\mathrm{C}_{2} \mathrm{H}_{5}\right)_{2}$.

In order to compare the reactivity of vinyl ether and styrene derivatives for a cationic reagent other than carbonium ion, chlorine was added to

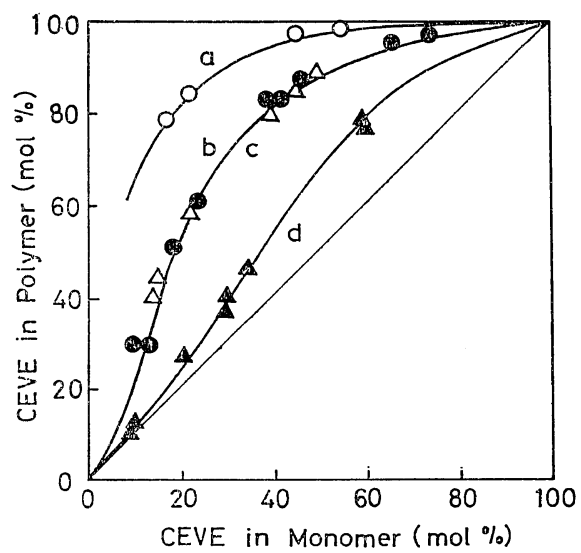

Figure 7. Copolymer composition curves of CEVE with $p$ MS.

([M] $\left.0.50 \mathrm{~mol} / l,-78^{\circ} \mathrm{C}\right)$

$\mathrm{a}(\mathrm{O}): \mathrm{BF}_{3} . \mathrm{OEt}_{2}, \mathrm{C}_{6} \mathrm{H}_{5} \mathrm{CH}_{3}, \mathrm{~b}(\triangle): \mathrm{BF}_{3} \mathrm{OEt}_{2}$, $\mathrm{CH}_{2} \mathrm{Cl}_{2}, \mathrm{c}\left(\mathrm{SnCl}_{4} \cdot \mathrm{CCl}_{3} \mathrm{CO}_{2} \mathrm{H}, \mathrm{C}_{6} \mathrm{H}_{5} \mathrm{CH}_{3}\right.$, $\mathrm{d}(\mathbf{\Delta}): \mathrm{SnCl}_{4} \cdot \mathrm{CCl}_{3} \mathrm{CO}_{2} \mathrm{H}, \mathrm{CH}_{2} \mathrm{Cl}_{2}$.

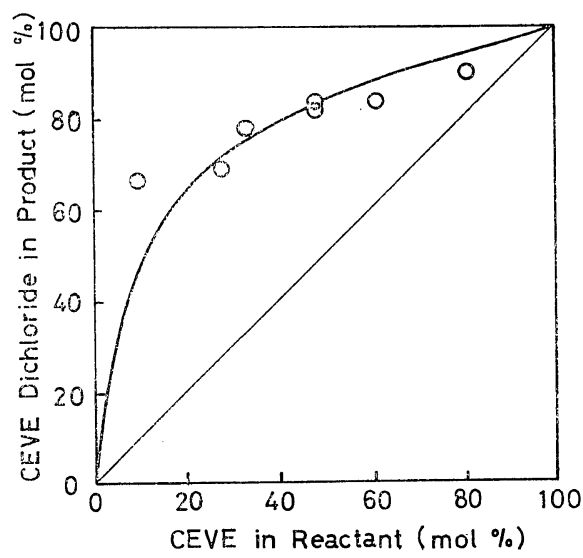

Figure 8. Relationship between the composition of initial products and that of monomers in the chlorine addition to CEVE- $p$ MS mixture.

([M]o $0.50 \mathrm{~mol} / l$, Solvent: $\mathrm{CH}_{2} \mathrm{Cl}_{2},-78^{\circ} \mathrm{C}$. Chlorine was bubbled slowly with oxygen into the solution.)

the mixture of CEVE and $p$ MS. It was confirmed that chlorination occurred on the vinyl group under the conditions shown in Figure 8. Figure 8 shows the relationship between reactant and product compositions. The reactivity of CEVE was appreciably larger than that of $p$ MS irrespective of reactant composition, and the composition curve in Figure 8 was not S-shaped as had 
Table II. Monomer reactivity ratios and $a$ and $K$ values calculated from Eq. 1 for the copolymerization of CEVE with $p \mathrm{MOS}$ and $p \mathrm{MS}^{\mathrm{a}}$

\begin{tabular}{|c|c|c|c|c|c|c|c|}
\hline Monomer & Catalyst & Solvent & $r_{1}$ & $r_{2}$ & $r_{1} \times r_{2}$ & $a$ & $K$ \\
\hline \multirow{4}{*}{$\begin{array}{l}\text { CEVE- } \\
p \text { MOS }\end{array}$} & $\mathrm{BF}_{3} \cdot \mathrm{OEt}_{2}$ & $\mathrm{C}_{6} \mathrm{H}_{5} \mathrm{CH}_{3}$ & $2.81 \pm 0.30$ & $4.37 \pm 0.30$ & 12.3 & 1.54 & 0.70 \\
\hline & "I & $\mathrm{CH}_{2} \mathrm{Cl}_{2}$ & $3.08 \pm 0.26$ & $4.55 \pm 0.35$ & 14.0 & 1.58 & 0.65 \\
\hline & $\mathrm{SnCl}_{4} \cdot \mathrm{TCA}^{\mathrm{b}}$ & $\mathrm{C}_{6} \mathrm{H}_{5} \mathrm{CH}_{3}$ & $1.73 \pm 0.19$ & $6.93 \pm 0.50$ & 12.0 & 1.54 & 0.36 \\
\hline & " & $\mathrm{CH}_{2} \mathrm{Cl}_{2}$ & $1.56 \pm 0.04$ & $7.80 \pm 0.20$ & 12.2 & 1.58 & 0.29 \\
\hline \multirow{4}{*}{$\begin{array}{l}\text { CEVE- } \\
p \mathrm{MS}\end{array}$} & $\mathrm{BF}_{3} \cdot \mathrm{OEt}_{2}$ & $\mathrm{C}_{6} \mathrm{H}_{5} \mathrm{CH}_{3}$ & - & - & - & $\sim 1.3$ & $\sim 27$ \\
\hline & "I & $\mathrm{CH}_{2} \mathrm{Cl}_{2}$ & $8.80 \pm 0.45$ & $0.40 \pm 0.03$ & 3.52 & 1.24 & 7.00 \\
\hline & $\mathrm{SnCl}_{4} \cdot \mathrm{TCA}^{\mathrm{b}}$ & $\mathrm{C}_{6} \mathrm{H}_{5} \mathrm{CH}_{3}$ & $10.1 \pm 1.8$ & $0.50 \pm 0.07$ & 5.05 & 1.32 & 7.40 \\
\hline & "I & $\mathrm{CH}_{2} \mathrm{Cl}_{2}$ & $2.31 \pm 0.17$ & $1.12 \pm 0.06$ & 3.71 & 1.27 & 2.10 \\
\hline
\end{tabular}

a $[\mathrm{M}]_{0} 0.50 \mathrm{~mol} / \mathrm{l},-78^{\circ} \mathrm{C}$

b TCA: Trichloroacetic acid.

Table III. Monomer reactivity ratios and $a$ and $K$ values calculated from Eq. 1 for the copolymerization of CEVE with $\alpha \mathrm{MS}$ at $-78^{\circ} \mathrm{C}^{\mathrm{a}}$

\begin{tabular}{clccccc}
\hline Catalyst & \multicolumn{1}{c}{ Solvent } & \multicolumn{1}{c}{$r_{1}$} & $r_{2}$ & $r_{1} \times r_{2}$ & $a$ & $K$ \\
\hline $\mathrm{BF}_{3} \cdot \mathrm{OEt}_{2}$ & $\mathrm{C}_{6} \mathrm{H}_{5} \mathrm{CH}_{3}$ & $5.72 \pm 0.70$ & $0.31 \pm 0.05$ & 1.77 & 1.05 & 5.00 \\
$\prime \prime$ & $\mathrm{CH}_{2} \mathrm{Cl}_{2}$ & $2.05 \pm 0.33$ & $0.68 \pm 0.14$ & 1.39 & 1.02 & 1.70 \\
$\mathrm{SnCl}_{4} \cdot \mathrm{TCA}^{\mathrm{b}}$ & $\mathrm{C}_{6} \mathrm{H}_{5} \mathrm{CH}_{3}$ & $3.46 \pm 0.25$ & $0.46 \pm 0.07$ & 1.59 & 1.03 & 3.20 \\
$\prime \prime$ & $\mathrm{CH}_{2} \mathrm{Cl}_{2}$ & $1.02 \pm 0.10$ & $1.00 \pm 0.10$ & 1.00 & 1.00 & 1.00 \\
\hline
\end{tabular}

a $[\mathrm{M}]_{0} 0.50 \mathrm{~mol} / l,-78^{\circ} \mathrm{C}$

b TCA: Trichloroacetic acid.

been the case in copolymerization. Therefore, the S-shape in copolymerization may be due to the existence of two types of carbonium ions, i.e. the propagating chain ends produced from CEVE and $p \mathrm{MS}$.

MRR were obtained through Fineman-Ross' method, which are listed in Table II. The products $r_{1} \times r_{2}$ were 11-16 in CEVE-pMOS and 3-5 in CEVE-pMS, which were clearly larger than unity.

As is clear in Figure 9, the linearity between log $\left(\left[\mathrm{M}_{1}\right] /\left[\mathrm{M}_{2}\right]\right)$ and $\log \left(d\left[\mathrm{M}_{1}\right] / d\left[\mathrm{M}_{2}\right]\right)$ was realized; the Eq. 1 proposed by O'Driscoll ${ }^{11,12}$ held in these systems;

$$
\frac{d\left[\mathbf{M}_{1}\right]}{d\left[\mathbf{M}_{2}\right]}=K\left(\frac{\left[\mathbf{M}_{1}\right]}{\left[\mathbf{M}_{2}\right]}\right)^{a}
$$

$a$ was $1.5-1.6$ in the CEVE-pMOS and 1.2-1.3 in the CEVE-pMS system. $K$ varied significantly, depending on the type of solvent and catalyst used.

\section{b. Copolymerization of CEVE with $\alpha M S$}

Polymerization conditions were the same as in the case of copolymerization with ring-sub-

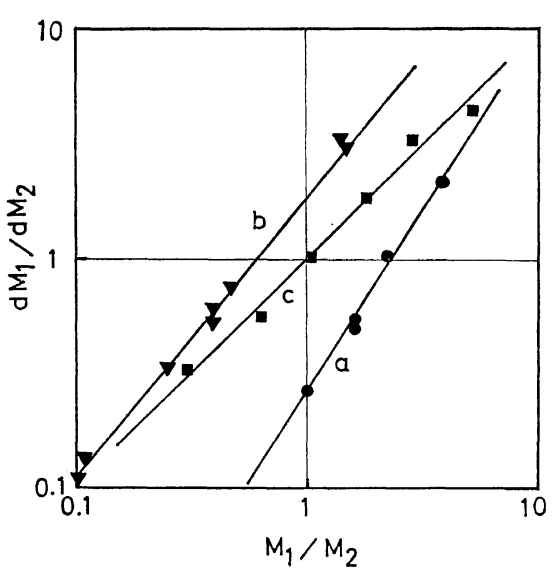

Figure 9. Relationship between $\log \left(\mathbf{M}_{1} / \mathbf{M}_{2}\right)$ and $\log \left(d \mathrm{M}_{1} / d \mathrm{M}_{2}\right)$ in the copolymerization of $\operatorname{CEVE}\left(\mathrm{M}_{1}\right)$ with styrene derivatives $\left(\mathbf{M}_{2}\right)$.

$\left([\mathrm{M}]_{0} 0.50 \mathrm{~mol} / l\right.$, Catalyst: $\mathrm{SnCl}_{4} \cdot \mathrm{CCl}_{3} \mathrm{CO}_{2} \mathrm{H}$, Solvent: $\mathrm{CH}_{2} \mathrm{Cl}_{2},-78^{\circ} \mathrm{C}$ )

$\mathrm{a}(\odot)$ : CEVE-pMOS, $\mathrm{b}(\boldsymbol{\nabla})$ : CEVE-pMS, c(ם): CEVE- $\alpha \mathrm{MS}$.

stituted styrenes. As shown in Figure 10, the reactivity of CEVE was larger than that of $\alpha \mathrm{MS}$ except 


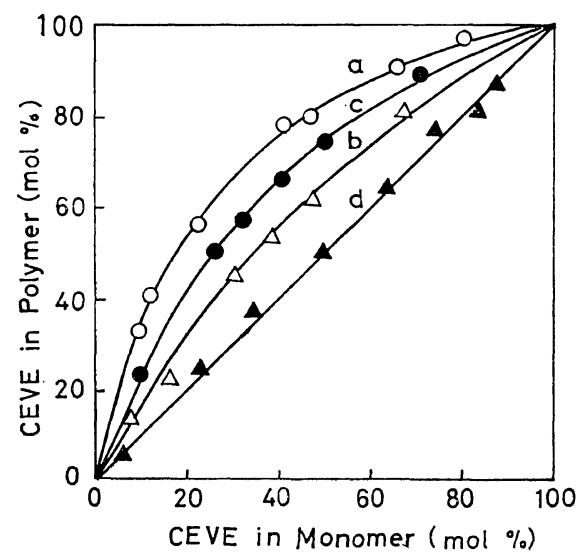

Figure 10. Copolymer composition curves of CEVE with $\alpha \mathrm{MS}$.

$\left([\mathrm{M}]_{0} 0.50 \mathrm{~mol} / \mathrm{l},-78^{\circ} \mathrm{C}\right)$

$\mathrm{a}(\mathrm{O}): \mathrm{BF}_{3} . \mathrm{OEt}_{2}, \mathrm{C}_{6} \mathrm{H}_{5} \mathrm{CH}_{3}, \mathrm{~b}(\triangle): \mathrm{BF}_{3}$. $\mathrm{OEt}_{2}, \quad \mathrm{CH}_{2} \mathrm{Cl}_{2}, \mathrm{c}(\mathrm{O}): \mathrm{SnCl}_{4} \cdot \mathrm{CCl}_{3} \mathrm{CO}_{2} \mathrm{H}$, $\mathrm{C}_{6} \mathrm{H}_{5} \mathrm{CH}_{3}, \mathrm{~d}(\Delta): \mathrm{SnCl}_{4} \cdot \mathrm{CCl}_{3} \mathrm{CO}_{2} \mathrm{H}, \mathrm{CH}_{2} \mathrm{Cl}_{2}$.

the case of the $\mathrm{SnCl}_{4} \cdot \mathrm{CCl}_{3} \mathrm{CO}_{2} \mathrm{H}$-methylene chloride system. The solvent and catalyst effects were conspicuously greater. $\alpha \mathrm{MS}$ content in the copolymer was larger in methylene chloride than in toluene, and by $\mathrm{SnCl}_{4} \cdot \mathrm{CCl}_{3} \mathrm{CO}_{2} \mathrm{H}$ than by $\mathrm{BF}_{3} \cdot \mathrm{O}\left(\mathrm{C}_{2} \mathrm{H}_{5}\right)_{2}$. These results were similar to those obtained in CEVE- $p$ MS system.

The values of MRR determined by the FinemanRoss method are listed in Table III. The product $r_{1} \times r_{2}$ was close to unity in all cases, which means that CEVE- $\alpha$ MS copolymerization is "ideal", that is, the relative reactivity of a monomer is independent of the type of growing carbonium ion. Plots of $\log \left(d \mathbf{M}_{1} / d \mathbf{M}_{2}\right)$ against $\log \left(\mathbf{M}_{1} / \mathbf{M}_{2}\right)$ gave straight lines, whose slopes were unity. $a$ and $K$ values are also shown in Table III.

\section{DISCUSSION}

\section{Formation of Copolymer}

In order to study the effect of polymerization conditions on the values of MRR in cationic copolymerization, it is convenient to select a pair of monomers whose reactivities are not so different, because the alternating tendency has not been observed in ionic copolymerization. ${ }^{2}$ The cationic polymerizability of vinyl ether is, in general, greater than that of styrene. Therefore, CEVE was used as vinyl ether, and styrenes with a electron-donating group were chosen as a styrene derivative.

In the copolymerization of CEVE with these styrene derivatives, no product other than methanol-insoluble polymer was observed. Formation of the copolymer was confirmed by fractionation and NMR spectra in the monomer pairs used here. Moreover, the molecular weights of the polymers produced were more than several thousands as shown in Figures 1 and 2. Therefore, in this paper attention is focused on the kinetic behavior in the copolymerization.

The Difference in Behavior between Ring-substituted Styrene and $\alpha M S$

The difference between ring-substituted styrenes and $\alpha \mathrm{MS}$ was clearly observed in the copolymerization with CEVE under the same conditions; the product $r_{1} \times r_{2}$ showed values larger than unity for ring-substituted styrenes, i.e. $p$ MOS and $p \mathrm{MS}$, while it showed that values are close to unity for $\alpha \mathrm{MS}$ irrespective of polymerization conditions.

On the other hand, in competitive chlorination CEVE was more reactive than $p \mathrm{MS}$ regardless of reactant composition. Therefore, it is concluded that the difference in selective reactivities of CEVE and $p$ MS cations can be ascribed to the character of the carbonium ion itself, and not to the influence of the counter-anion and solvent. ${ }^{8}$ One of the reasons for the difference in the behavior between ring-substituted styrenes and $\alpha \mathrm{MS}$ might be that the $\alpha \mathrm{MS}$ cation is more stable than the $p \mathrm{MOS}$ and $p \mathrm{MS}$ cation. In gas phase, it was reported that the stabilization energy of the carbonium ion $\mathrm{CH}_{3} \mathrm{O}_{\mathrm{C}}^{+} \mathrm{H}_{2}$ was almost the same as that of the isopropyl carbonium ion. ${ }^{13}$ Therefore, the stability of $(\alpha \mathrm{MS})^{+}$seems to be similar to that of (MVE) $)^{+}$, but that of (ring-substituted styrene $)^{+}$will be less than that of $(\mathrm{MVE})^{+} \cdot{ }^{14}$ These results suggest that the cross-propagation reaction in copolymerization can be more easily achieved between monomers whose carbonium ions possess a similar degree of stability, even in cases where the type of substituent is different. Further study and experiment will be necessary before this problem can be resolved.

The Effect of Polymerization Conditions on the Relative Reactivity of Both Monomers

The relative reactivity of the monomer can be 
easily estimated from MRR in the CEVE- $\alpha$ MS system, as $r_{1} \times r_{2} \simeq 1$. The reactivity of CEVE is 1.7-5.0 times larger than that of $\alpha \mathrm{MS}$ except the case of $\mathrm{SnCl}_{4} \cdot \mathrm{CCl}_{3} \mathrm{CO}_{2} \mathrm{H}$-methylene chloride in which both reactivities are equal.

The relative reactivities of the monomers were changed by the type of propagating ends in the CEVE- $p$ MOS and the CEVE- $p$ MS systems. In this case the relative reactivity can be tentatively considered as the polymer composition in the copolymerization of equimolar monomer composition. The $K$-values in Eq. (1) could be used as its index. According to $K$-values, CEVE had smaller reactivity than $p \operatorname{MOS}(K=0.3-0.8)$, and larger than $p \mathrm{MS}(K=2-27)$.

It is well known that the kind of solvent and catalyst used affects MRR in ionic copolymerization. A tendency was recognized in the influence of the catalyst: the styrene derivative content in the copolymer increased in every system irrespective of the relative reactivity of monomers, whenever $\mathrm{SnCl}_{4} \cdot \mathrm{CCl}_{3} \mathrm{CO}_{2} \mathrm{H}$ was used instead of $\mathrm{BF}_{3}$. $\mathrm{O}\left(\mathrm{C}_{2} \mathrm{H}_{5}\right)_{2}$. Using $\mathrm{SnCl}_{4} \cdot \mathrm{CCl}_{3} \mathrm{CO}_{2} \mathrm{H}$ as catalyst, the relative reactivity in the $\mathrm{CEVE}-\alpha \mathrm{MS}$ and CEVE- $p$ MS systems approached unity, while it tended to be greater than unity, conversely, in CEVE-pMS systems. Therefore, this catalyst effect cannot be explained by the concept proposed by Tobolsky et al. ${ }^{15}$ that the selectivity for monomers is decreased with the increase in the reactivity of growing ions. It is concluded that $\mathrm{SnCl}_{4} \cdot \mathrm{CCl}_{3} \mathrm{CO}_{2} \mathrm{H}$ is more favorable in the polymerization of styrene derivatives than $\mathrm{BF}_{3}$. $\mathrm{O}\left(\mathrm{C}_{2} \mathrm{H}_{5}\right)_{2}$, though the reason for this is not clear at present.

CEVE content in the copolymers increased in non-polar solvent in the copolymerization with non-polar monomers, such as $\alpha \mathrm{MS}$ and $p \mathrm{MS}$. There have been two possible explanations for the influence of solvents on copolymer composition. ${ }^{15,16}$ One is "the decrease in the selectivity of the addition of an ion for each monomer with the increase in the reactivity of an ion", proposed by Tobolsky et al. ${ }^{15}$ The other is "the selective solvation to propagating end by a polar monomer in a non-polar solvent", proposed by Overberger et $a .^{16}$ Considering the catalyst effect, the former explanation seems to be unsuitable. It is therefore suggested that "selective solvation" is the predominant factor in the solvent effect in these reactions.

\section{REFERENCES}

1. e.g., C. G. Overberger, L. H. Arnold, and J. J. Taylor, J. Amer. Chem. Soc., 73, 5541 (1951).

2. Y. Landler, J. Polym. Sci., 8, 63 (1952).

3. D. D. Eley and J. Saunders, J. Chem. Soc., 1954, 1677.

4. J. F. Dunphy and C. S. Marvel, J. Polym. Sci., 47, 1 (1960); J. Org. Chem., 25, 2209 (1960).

5. N. Kanoh, K. Ikeda, A. Gotoh, T. Higashimura, and S. Okamura, Makromol. Chem., 86, 200 (1965).

6. T. Higashimura, J. Masamoto, and S. Okamura, Kobunshi Kagaku, 26, 702 (1968).

7. H. Yuki, K. Hatada, and M. Kakeshita, $J$. Polym. Sci., Part A-1, 7, 667 (1969).

8. G. R. Brown and D. C. Pepper, J. Chem. Soc., 1963, 5930.

9. Y. Imanishi, T. Higashimura, and S. Okamura, J. Polym. Sci., Part A 3, 2455 (1965).

10. T. Higashimura, T. Masuda, and S. Okamura, J. Polym. Sci., Part A-1, 7, 1115 (1969).

11. K. F. O'Driscoll, J. Polym. Sci, 57, 721 (1962).

12. T. Higashimura, T. Masuda, and K. F. O'Driscoll, J. Polym. Sci., Part B, 6, 841 (1968).

13. R. H. Martin, F. W. Lampe, and R. W. Taft, $J$. Amer. Chem. Soc., 88, 1353 (1966); 87, 2490 (1965).

14. J. Halpern, J. Chem. Phys., 20, 744 (1952).

15. A. V. Tobolsky and R. J. Boudreau, J. Polym. Sci., 51, S53 (1961).

16. C. G. Overberger and V. G. Kamath, J. Amer. Chem. Soc., 81, 2190 (1959); 85, 446 (1963). 